\title{
Analysis of pre-vault tunnelling interaction with buildings
}

Alan G. Bloodworth MA, MSc, DIC, DPhil, CEng, MICE Principal Teaching Fellow in Tunnelling and Underground Space, School of Engineering, University of Warwick, Coventry, UK: formerly Kellogg Brown \& Root, Leatherhead, UK

(corresponding author: a.bloodworth@warwick.ac.uk)
Guy T. Houlsby MA, DSC, FREng, FICE

Professor of Civil Engineering, Department of Engineering Science, University of Oxford, Oxford, UK

This paper presents data from a case history of tunnelling using the pre-vaulting method, at low cover and without compensation grouting, beneath a terrace of masonry buildings at Ramsgate, Kent. Surface and building settlements were measured and movements on existing cracks monitored throughout construction. Volume loss was low and the settlement trough quite narrow. Buildings responded flexibly with lower damage level than predicted by assessment using a deep beam analogy. Damage was concentrated in opening of existing cracks, with the only significant new cracks likely to have their origin in three-dimensional effects as the tunnel heading approached the buildings. Assessment of tunnelling effects on buildings is important to confirm the viability of new tunnelling projects and reassure building owners of the possible level of damage, while avoiding excessive conservatism. Numerical modelling shows potential for such assessment, and a procedure for modelling the ground, tunnel and building together using non-linear three-dimensional finite-element analysis has been applied to this site. It was found that, although geometry and other features of the site required simplification due to practical limitations in computing resources, model results still reflected the main features of observed response including the 'greenfield' trough, flexible structure response and damage severity.

\section{Introduction}

This paper presents a case history of tunnelling using the pre-vaulting technique (Morgan, 1999), beneath existing buildings at Ramsgate, Kent. Extensive monitoring of both ground movements and damage to buildings (specifically crack opening) was carried out as the Ramsgate Harbour tunnel was constructed directly beneath a terraced row of houses. The observations are compared with a coupled three-dimensional finite-element analysis of the construction. The complexities of both the pre-existing buildings and of the tunnel construction necessitated simplifications in the finite-element analysis. The benefits and limitations of the analysis are explored in order to evaluate the method as a tool for prediction in similar circumstances.

\section{Ramsgate Harbour tunnel case study}

The $2 \cdot 2 \mathrm{~km}$ Ramsgate Harbour Approach Road was constructed in 1998/99. The single-carriageway route passes through a single-bore, 800 -m-long tunnel under the chalk cliffs (Figure 1). A terrace of cottages at the west end of the drive, originally due to be demolished for a cut-and-cover section, was saved and became a focus of interest for monitoring of ground and structure movements.

\subsection{Ground conditions}

A detailed ground investigation was carried out prior to construction (Huntley et al., 1997). At the west end of the drive in the area of the cottages, there is approximately $1 \mathrm{~m}$ of made ground overlying 2-3 m of red 'brickearth', classified as lowto intermediate-plasticity clay with a substantial silt fraction. Beneath this is weathered chalk CIRIA grade B4 to Dm (CIRIA, 1994), overlying competent Upper Chalk, CIRIA grade $\mathrm{B} 2 / \mathrm{B} 3$.

Ground strata encountered within the tunnel envelope are shown in Newman and Ingle (2002). At the cottages, a buried river valley increases the depth of chalk weathering significantly. The invert lies in competent chalk, but the crown passes through weathered to highly weathered chalk grades Dc to Dm, classified on site as low-plasticity clay. Chalk cover over the crown is only 1-2 $\mathrm{m}$, with the brickearth and made ground overlying.

Groundwater was predicted to be present only in the invert in the deeper part of the drive, under high tide conditions (Newman et al., 2003), and was therefore not expected to significantly impact tunnelling operations.

\subsection{Tunnel construction}

The Ramsgate tunnel was the first use in the UK of the prevaulting method (Morgan, 1999). The tunnel is approximately $11 \mathrm{~m}$ in diameter, with an arched profile and flat invert. In the pre-vaulting method, a slot is cut in stages around the sides and crown of the tunnel face and a primary lining or 'prevault' is cast by spraying concrete into the slot to provide 


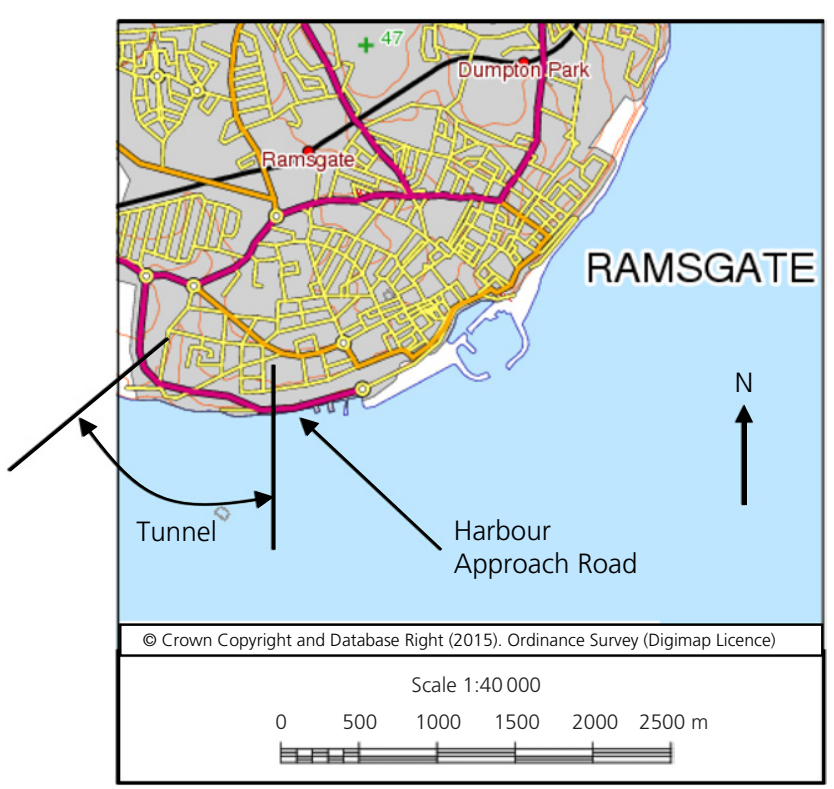

Figure 1. Location of tunnel advanced support (Crow and Newman, 1999). The method is also known as the 'mechanical pre-cutting method' from its origins in Europe (Bougard, 1988; Martareche, 2013), where it has found favour for relatively short drives at low cover and/or in variable ground conditions. The face is temporarily reinforced with glass fibre face bolts and then advanced using standard excavation equipment, and the flat invert slab is cast, enabling the machine to move forward for the next construction cycle. Radial rock bolts were also installed in the lower haunch regions. Illustrations of the full pre-vaulting sequence are given by Newman and Ingle (2002). A secondary lining of in situ reinforced concrete is cast later as a separate operation.

The strength of the primary lining may be adjusted to suit ground conditions by varying the pre-vault overlaps. At Ramsgate, the length of advance per cycle of operations varied from $2.5 \mathrm{~m}$ to $4.5 \mathrm{~m}$, with each cycle taking typically $24 \mathrm{~h}$. Greater overlaps were used in the vicinity of the cottages.

\subsection{Buildings}

The tunnel passed at $40^{\circ}$ skew beneath a terrace of eight cottages (Figure 2) with a cover of only $6 \mathrm{~m}$ (approximately half a diameter). The cottages date from the early 1900s and

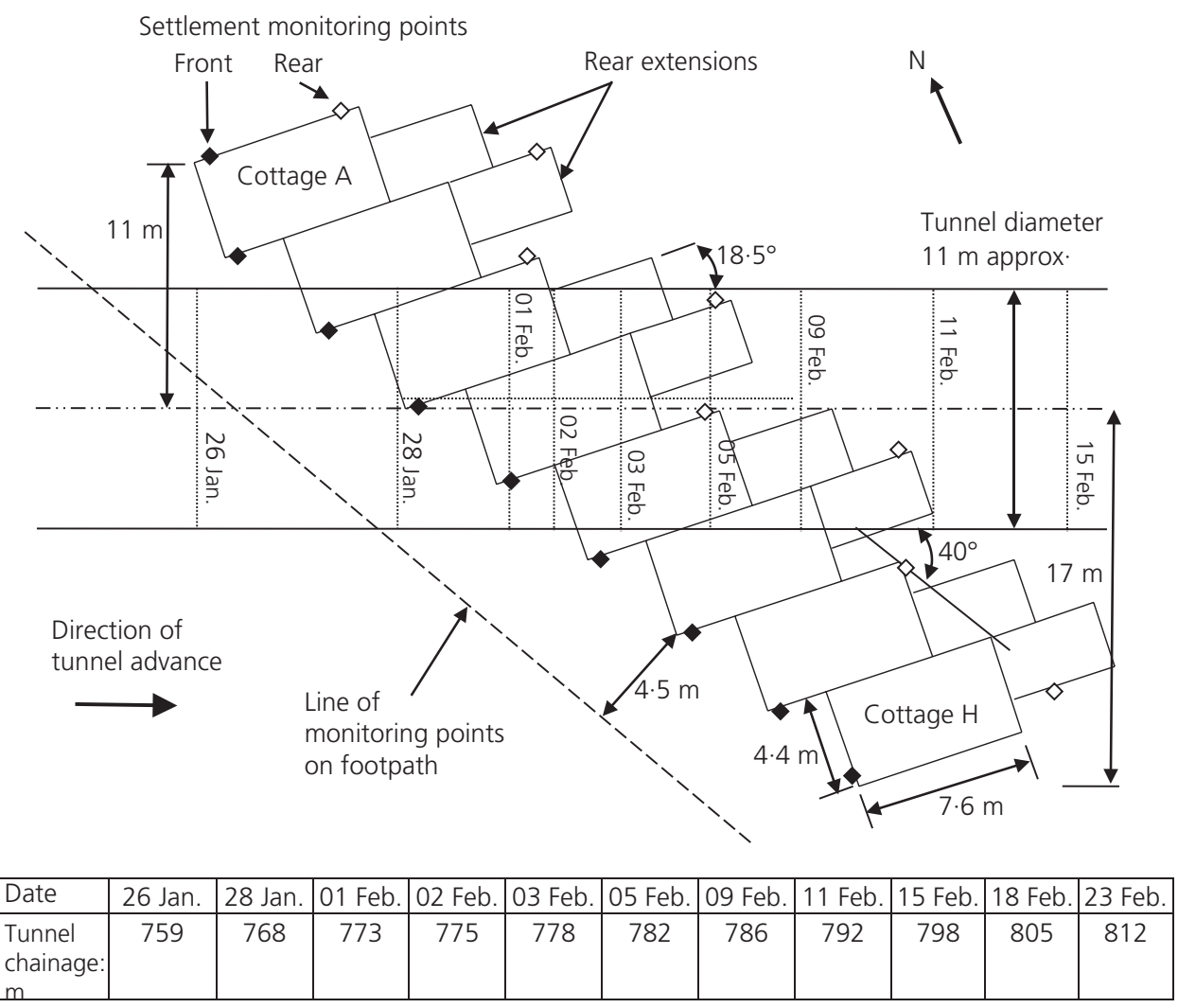

Figure 2. Plan showing location of cottages and settlement monitoring points relative to tunnel alignment and heading advance 
are two-storey with no basements (Figure 3). Each cottage has an extension wing at the back, and is staggered relative to the next by $2 \mathrm{~m}$. The structural form is load-bearing brick masonry (solid $220 \mathrm{~mm}$ thick) on shallow strip foundations, with timber suspended floors and ceilings. Although some alterations have taken place, the main load-bearing walls front, rear and party walls - have been retained, along with the important openings to the front and rear.

Structural surveys of the cottages were carried out prior to tunnel construction. The majority were found to be in good condition, with only occasional hairline cracking. However, cottage $\mathrm{H}$ at the south end was extensively cracked, due to previous ground movements. Since it lay outside the predicted settlement trough, it was not expected to be directly affected by the tunnelling settlements, and this was confirmed by the monitoring.

\section{$2.4 \quad$ Monitoring}

Transverse arrays of precise levelling points in a field to the west of the cottages gave an indication of the 'greenfield' settlement response to the advancing tunnel. However, the ground conditions in this area were distinct from those at the cottages, with loose, blocky chalk of grades C4/C5 encountered in the crown that caused problems of localised failure of the prevault slots, necessitating grouting to be used (Newman and Ingle, 2002). No grouting was necessary at the cottages. The settlement array most closely representing 'greenfield' settlements in the vicinity of the cottages was located along the footpath, about $4 \mathrm{~m}$ in front of the cottage facades. The contractor also carried out comprehensive in-tunnel monitoring throughout the project (Crow and Newman, 1999; Morgan, 1999).
Monitoring of the cottages was specified as part of this research project. Precise levelling studs were grouted at each end of the party walls between cottages, to measure settlements at the front and rear. Crack telltales were used on the larger pre-existing cracks in cottage $\mathrm{H}$. Demec arrays were located on smaller (typically 1-2 mm wide) pre-existing cracks on the external faces of other cottages, often located close to windows and doors, as detailed in Table 1. For convenience, arrays were located no more than $2.5 \mathrm{~m}$ above ground, but there were no significant pre-existing cracks above this level.

A baseline survey of the instruments was carried out 2 months before tunnelling. Daily monitoring began when the tunnel heading was $30 \mathrm{~m}$ from the cottages. The face passed under the front of the cottages 11 days later, and daily monitoring continued for a further 25 days, at which time the face had advanced to $15 \mathrm{~m}$ beyond the southern end of the cottages. Monitoring continued at weekly intervals for 5 weeks.

\subsection{Observed settlements}

The development of the settlement troughs at the front and rear of the cottages is shown in Figures 4 and 5, where the offset from the tunnel centreline is measured perpendicular to the tunnel axis direction in all cases. Limiting settlements were reached after 2 weeks from when settlements due to tunneling were first discernible, although the majority of settlement occurred in the first $4 \mathrm{~d}$.

Final settlement troughs are shown in Figure 6 (including the footpath). Maximum settlements were $12.8 \mathrm{~mm}$ on the footpath, $13.4 \mathrm{~mm}$ at the front of the cottages and $18.4 \mathrm{~mm}$ at the rear; the greater value at the rear was probably due to lower

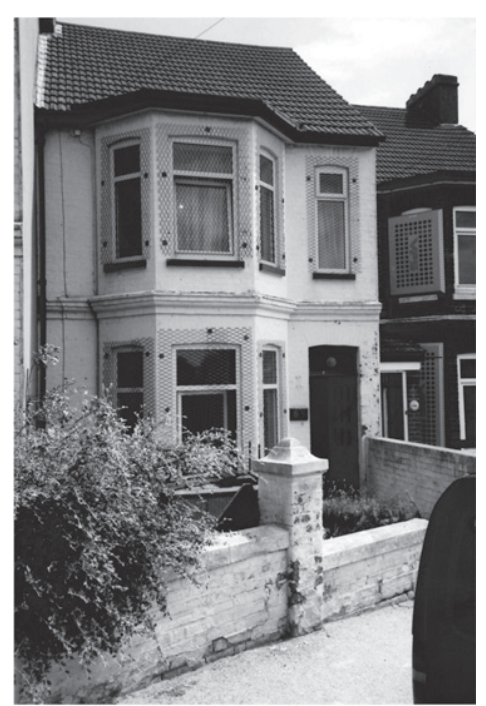

(a)

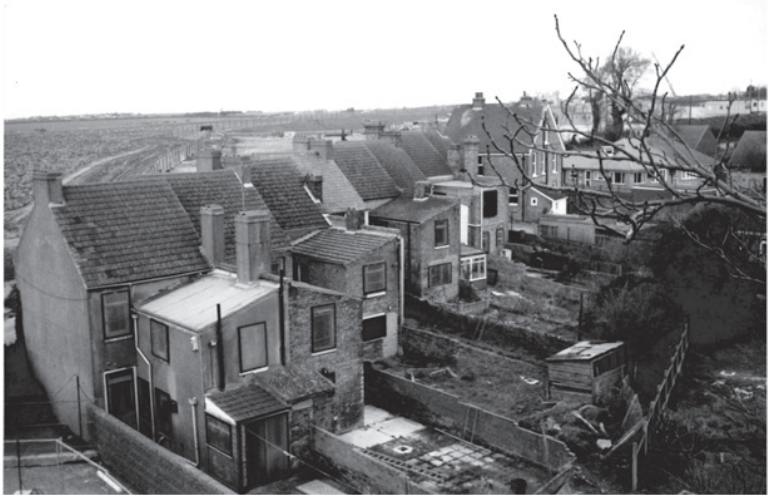

(b)

Figure 3. Views to the (a) front and (b) rear of terrace of cottages 


\begin{tabular}{|c|c|c|c|}
\hline Demec array & Cottage & Location & Description \\
\hline D1 & $\mathrm{H}$ & Side & Right side of wall, $1 \mathrm{~m}$ above ground \\
\hline D2 & $\mathrm{H}$ & Side & Centreline of wall, close to ground \\
\hline D3 & $\mathrm{H}$ & Side & Centreline of wall, $500 \mathrm{~mm}$ above ground level \\
\hline D4 & $\mathrm{H}$ & Side & Centreline of wall, $1 \mathrm{~m}$ above ground level \\
\hline D5 & $\mathrm{H}$ & Front & Beneath ground floor bay window, on right side \\
\hline D6 & $\mathrm{H}$ & Front & Beneath ground floor bay window, on left side \\
\hline D7 & $\mathrm{D}$ & Front & Beneath ground floor bay window, on centreline \\
\hline D8 & $\mathrm{D}$ & Front & Beneath ground floor bay window central pane, on right side \\
\hline D9 & A & Side & $1 \mathrm{~m}$ above ground, $1.5 \mathrm{~m}$ from right end \\
\hline D10 & A & Side & $1 \mathrm{~m}$ above ground, $1.5 \mathrm{~m}$ from left end \\
\hline D11 & A & Rear & $500 \mathrm{~mm}$ above ground on left side \\
\hline D12 & G & Rear & Above rear window \\
\hline D13 & B & Rear & Top right corner of larger rear window \\
\hline D14 & $\mathrm{D}$ & Rear & Below rear window, on right side \\
\hline D15 & $\mathrm{F}$ & Rear & Above rear window, on left side \\
\hline D16 & $\mathrm{F}$ & Rear & Above rear window, on right side \\
\hline D17 & G & Rear & On side wall of rear extension, above left window on centreline of window \\
\hline D18 & $\mathrm{H}$ & Rear & On side wall of rear extension, above left window \\
\hline D19 & G & Front & Side rendered wall of cottage $F$, lower left corner \\
\hline D20 & G & Front & Side rendered wall of cottage $\mathrm{F}$, right side $2 \mathrm{~m}$ above ground level \\
\hline D21 & $\mathrm{E}$ & Front & Beneath ground floor bay window, on centreline \\
\hline D22 & $\mathrm{D}$ & Front & Above ground floor bay window, on centreline \\
\hline D23 & $\mathrm{C}$ & Front & Above left pane of ground floor bay window \\
\hline D24 & $\mathrm{H}$ & Front & On concrete window sill of ground floor bay window, central pane \\
\hline
\end{tabular}

Table 1. Locations of Demec arrays on cottages



Figure 4. Development of settlement trough along front facades of cottages 


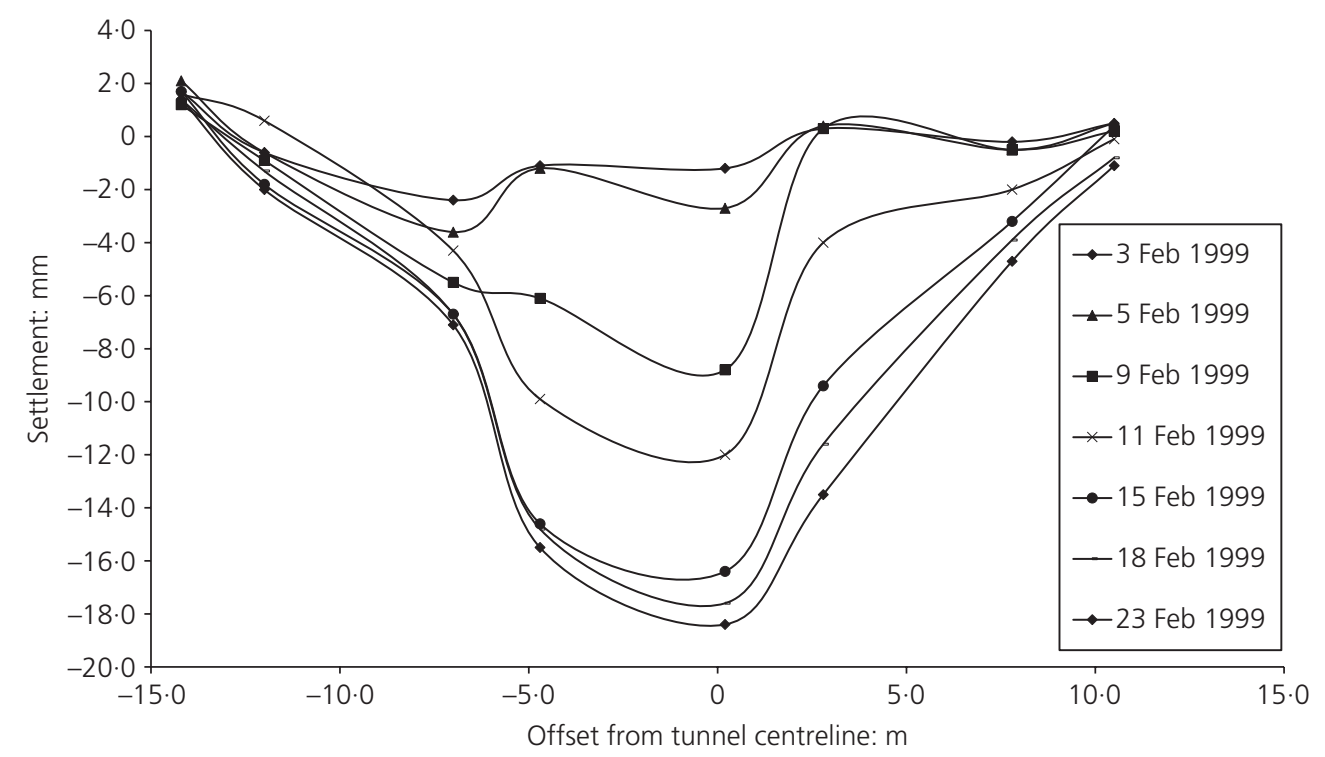

Figure 5. Development of settlement troughs along rear facades of cottages



Figure 6. Final settlement troughs observed on site and predicted by 'greenfield' model

chalk cover and greater depth of brickearth above the tunnel. If an approximation is made to the empirical Gaussian model for surface settlements due to tunnelling (Peck, 1969), the trough width parameter $i$ may be obtained from the gradient of a graph of the transverse co-ordinate from the tunnel axis $y$ squared against the natural logarithm of the ratio of maximum settlement $S_{\max }$ to settlement $S$ at transverse co-ordinate $y$. This has been done in Figure 7, which gives $i$ equal to $6.6 \mathrm{~m}$ on the footpath, $4.5 \mathrm{~m}$ at the front of the cottages and $5.2 \mathrm{~m}$ at the rear (perpendicular to the tunnel axis direction in 


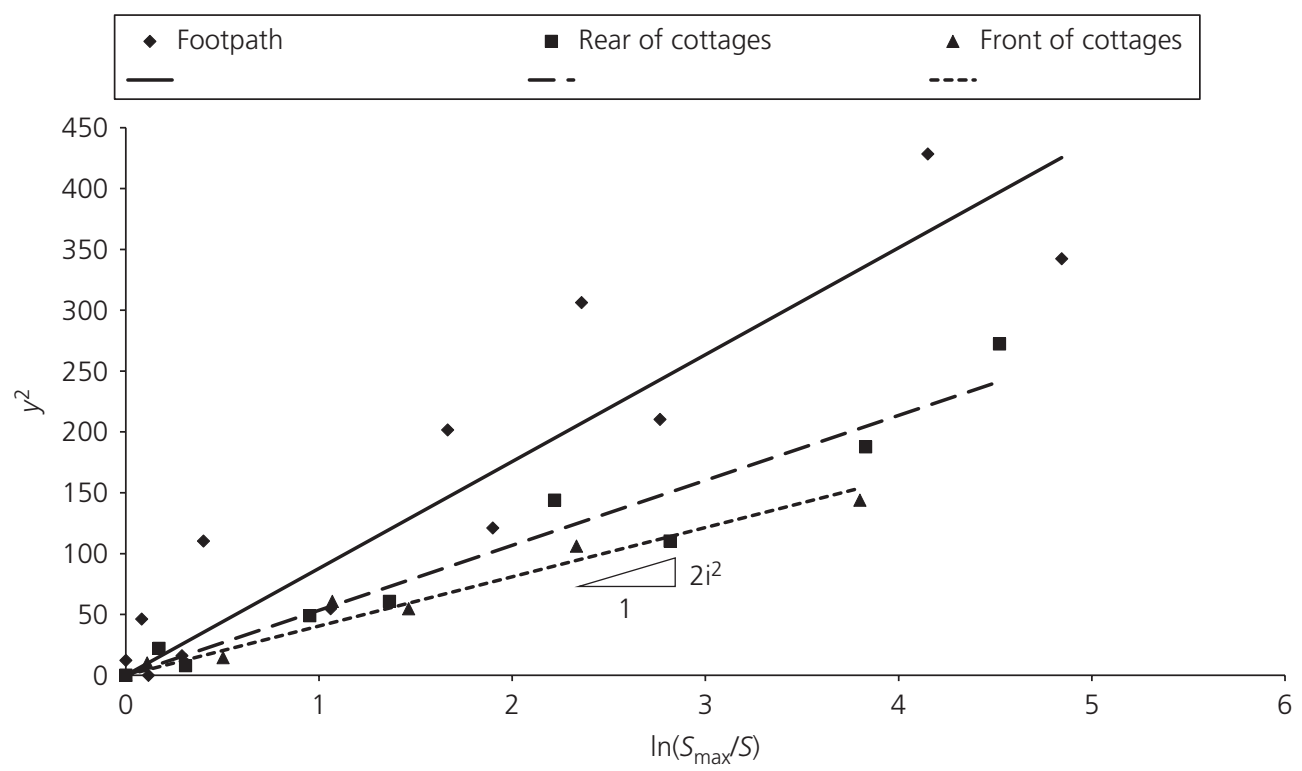

Figure 7. Graph of transverse distance squared against $\ln \left(S_{\max } / S\right)$

to derive trough width parameter $i$

all cases). Although on the footpath and at the rear of the cottages the trough shape appears visually to deviate from the Gaussian model, Figure 7 shows it is nevertheless still possible to approximate it as such, although scatter is more for the footpath data.

These results suggest that the buildings responded in a relatively flexible manner, not modifying the 'greenfield' trough (as represented by the footpath) significantly (Franzius et al., 2004). Volume loss calculated from the integral of the observed troughs is $0 \cdot 19 \%$ at the footpath, $0 \cdot 14 \%$ at the front of the cottages and $0 \cdot 21 \%$ at the rear.

The depth $z_{0}$ to the tunnel axis at the cottages is about $11 \mathrm{~m}$, and hence the ratio $i / z_{0}$ lies in the range $0 \cdot 40-0 \cdot 50$, typical for cohesive materials. However, later in the drive, as the tunnel advanced into competent chalk and $z_{0}$ increased to over $20 \mathrm{~m}$, the trough width remained almost unchanged, with $i$ equal to approximately $5 \mathrm{~m}$ (figure 5 of Crow and Newman (1999)), and $i / z_{0}$ therefore decreasing to $0 \cdot 2$ - a narrow trough width relative to tunnel depth. This suggests that the origin of the settlements is at the crown of the tunnel (rather than distributed around the cross-section, as is more typical in conventional bored tunnelling) - either deflection of the primary lining at the crown or volume loss localised in the crown region prevaults. Crown deflections of $5 \mathrm{~mm}$ and convergence of $2-5 \mathrm{~mm}$ was recorded in the region of the cottages (Crow and Newman, 1999).

\subsection{Effects on structures}

Movements on existing cracks monitored with Demec arrays on cottages $A$ to $G$, where the total movement at the end of the monitoring period was $0.05 \mathrm{~mm}$ or greater, are shown in Figures 8 and 9. ' $\mathrm{D} x$ ' denotes horizontal movement and ' $\mathrm{D} y$ ' denotes vertical movement. Movements are strongly correlated in time with the arrival of the tunnel face on 1 February. The magnitudes, at $0 \cdot 4-0.5 \mathrm{~mm}$, correlate with damage category 'Very slight' according to the classification of Burland et al. (1977). Based on the observed settlement trough, the method of Burland and Wroth (1975) predicts a higher damage category of 'Slight'.

Cracks with detectable movements are concentrated on cottages B to E, close to or over the tunnel. Two conclusions can be drawn. The first is that small cracks in masonry buildings may remain stable over a typical 4-month period if not subjected to significant ground movements. The second is that response of a masonry building to ground settlements includes movements on existing cracks. Therefore, an understanding of the initially cracked state is important.

The data show that more cracks closed up due to the tunnelling than opened further. Location of active cracks vertically on the facades, and their position in the hogging or sagging regions of the settlement trough, may be compared to the deep beam analogy of building response (Burland and Wroth, 1975), which states that a building located over the hogging region of the settlement trough will experience flexure with the neutral axis for bending at ground level, whereas a building spanning the sagging region of the settlement trough will deform with the neutral axis at mid-height of the building. However, conclusions from this comparison with the beam analogy are not clear-cut. For example, D11 is close to ground 


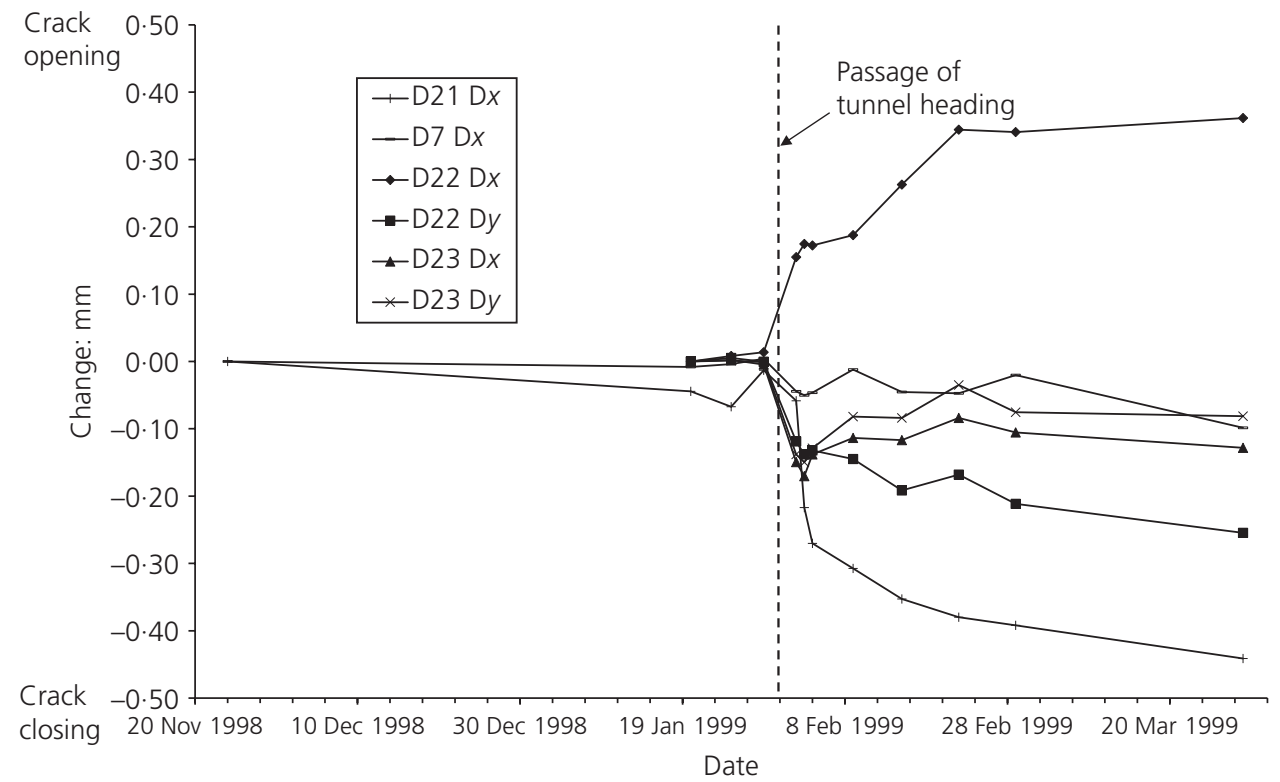

Figure 8. Movements of existing cracks on front facades of cottages

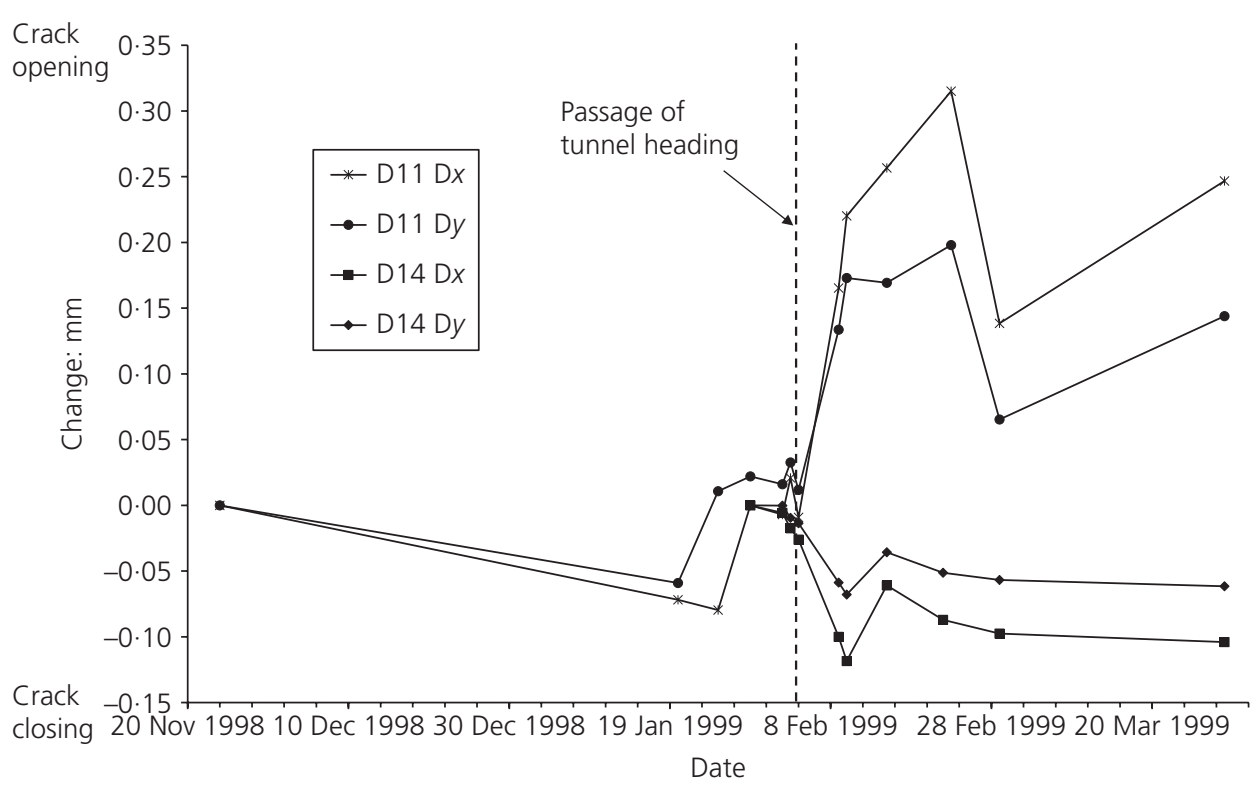

Figure 9. Movements of existing cracks on rear facades of cottages

level in the hogging region and opened by about $0.25 \mathrm{~mm}$, which is consistent with the facade acting as a deep beam with neutral axis at foundation level. However, D21, also low down in the hogging region, closed. D14, low down in the sagging region (where tension is expected), closed. D22, just above a ground floor window in the sagging region (where low strain is expected), opened, but D23 at the same level in the same region closed.
Inspection of the cottages 1 month after the tunnel had passed highlighted only two significant new cracks

(a) internal, penetrated through party wall between $\mathrm{C}$ and $\mathrm{D}$, on first floor towards the rear; vertical, typically $1.5 \mathrm{~mm}$ wide

(b) internal, in party wall between $\mathrm{C}$ and $\mathrm{D}$, not penetrated through but only visible from $\mathrm{D}$, running vertically for 
most of height of stair opening, typically $1.0 \mathrm{~mm}$ wide, maximum $2.0 \mathrm{~mm}$ at the top.

Both these cracks are consistent with cottages $\mathrm{C}$ and $\mathrm{D}$ being subjected to greater settlement at the rear than at the front, as supported by the observed settlement troughs (Figures 4 and 5).

\section{Numerical modelling of tunnel-building interaction}

Three-dimensional finite-element modelling procedures have been developed to predict the effects of tunnelling on surface structures, in which the ground, tunnelling process and building are all included in a 'coupled' model (Figure 10). This is an advance on assessment techniques that apply 'greenfield' settlements to a model of the building alone, many of which fail to capture the influence of the building weight and stiffness in modifying the ground movements (Farrell et al., 2014). These interaction effects have been shown to be significant in cases such as the Jubilee Line Extension (Burland et al., 2001). Although modelling in three dimensions requires considerably greater computing resources, it is necessary to represent adequately most real sites (Mair, 1993), as a tunnel and buildings may be arranged in any orientation and plane strain analysis may involve unacceptable oversimplification.

The procedures were initially demonstrated by idealised example analyses of a shallow tunnel in clay soil beneath a masonry building (Burd et al., 2000). These showed that the stiffness of the building smoothed the settlement trough, reducing differential settlements and damage compared to simplified methods that apply 'greenfield' settlements to the building. The importance of building weight in causing increased settlements locally beneath the building was also shown, as noted by others (e.g. Franzius et al., 2004; Mroueh and Shahrour, 2002). Building geometry relative to the tunnel and distribution of stiffness

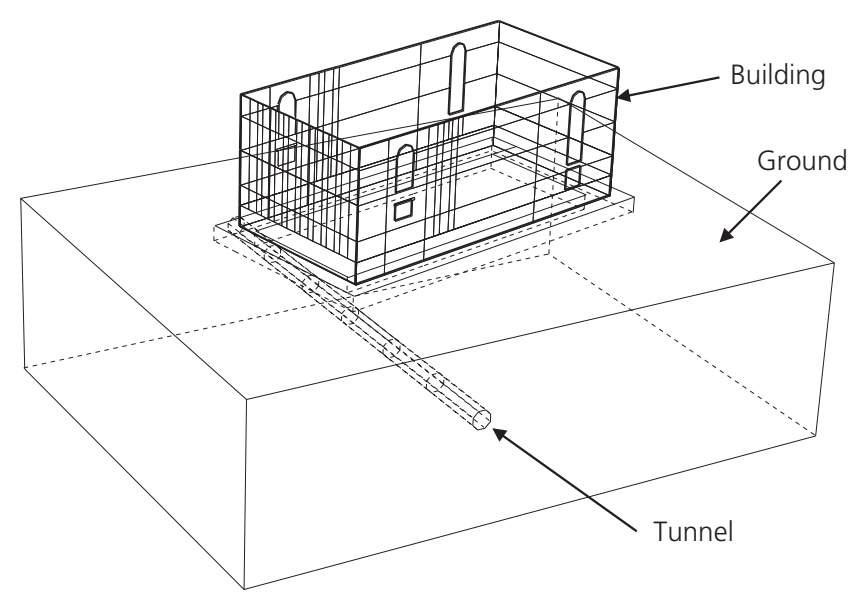

Figure 10. A coupled model of ground, tunnel and building within the building (e.g. presence of significant openings in the walls) was found to influence the response and damage more than the absolute value of building stiffness.

The modelling procedures were then verified against case history data from three sites (Bloodworth, 2002): a shaft close to a masonry church (Bloodworth and Houlsby, 2000), Ramsgate Harbour tunnel and a pedestrian tunnel beneath the Mansion House, London (Frischmann et al., 1994). These sites were chosen because no intervention measures such as compensation grouting had been used. Inclusion of compensation grouting has been considered in a parallel project (Wisser et al., 2001).

The procedures have application both in enabling better understanding of mechanisms of response of masonry buildings to tunnelling, and potentially as a design tool when a building fails the initial stage of assessment in which the 'greenfield' settlement profile is imposed on a structural model of the building (Mair et al., 1996). This paper aims to demonstrate how an analyst could apply the procedures in practice, in which one of the main challenges is to identify appropriate simplifying assumptions while retaining the essential core of the analytical methods.

\section{Modelling procedures}

Details of the procedures, which were implemented in the Oxford in-house program 'Oxfem' are given by Burd et al. (2000). The main features are listed below.

(a) Tunnel excavation is modelled explicitly by removing soil elements and activating elements to model a tunnel lining.

(b) Ground is modelled by tetrahedral solid elements, in an unstructured mesh that allows greater refinement close to the building and tunnel, and also can accommodate awkward and skewed geometry.

(c) The tunnel lining may be either shell elements, of an overlapping faceted type that are compatible with solid elements (Phaal and Calladine, 1992), or thin continuum elements (Augarde and Burd, 2001). In this case study, shell elements were used.

(d) Volume loss is modelled by artificially shrinking the lining in the circumferential direction by specified strain. Because lining stiffness is high relative to the surrounding soil, soil restraint to this shrinkage is not significant, so that volume loss may be controlled by this method. For example, $1 \%$ shrinkage strain imposed on the whole lining causes $2 \%$ reduction in tunnel cross-sectional area, modelling $2 \%$ volume loss. Stresses in the vicinity of the tunnel will be unrealistic, but ground movements away from the tunnel are calculated satisfactorily.

(e) The masonry building is modelled as a series of connected facades. Lighter, more flexible elements such as floors and roof are neglected. Walls are modelled by 
plane stress elements and are tied together and to the ground using displacement constraints, implemented as independent 'tie' elements (Houlsby et al., 2000). An alternative approach in which facades are modelled as beams with equivalent stiffness tied to the ground has also been demonstrated (Pickhaver et al., 2010).

( $f$ ) Constitutive models for the ground and building reproduce the material behaviour relevant to the problem.

(g) For stiff undrained clay, a multi-surface plasticity model is used (Houlsby, 1999) reflecting higher stiffness of soil observed at very small strains. In principle, any model capable of representing small strain pre-failure behaviour of soil could be used, subject to verification.

(h) Masonry is modelled as an elastic no-tension material, that is, with a low tensile strength and infinite compressive strength, using a smeared cracking approach. If the minor principal strain becomes tensile at an integration point, a crack is deemed to have formed perpendicular to this strain, and the material stiffness perpendicular to the crack is reduced sharply to a small nominal value. The direction of the crack does not change with subsequent loading. The component perpendicular to the crack of any subsequent strain taking place is output as the 'cracking strain', and used as a measure of damage severity, analogous to the use of maximum tensile strain in an elastic model of a building subjected to 'greenfield' settlements (Boscardin and Cording, 1989; Burland and Wroth, 1975).

\section{Modelling strategy and assumptions}

\subsection{Overview}

A reasonable understanding of the 'greenfield' settlement response of the ground was obtained at Ramsgate. The first priority in numerical modelling was to reproduce this 'greenfield' behaviour. Buildings were then added to form the coupled model. Emphasis was placed on studying the response of the terrace of cottages as a whole.

\subsection{Ground}

To model the site, simplifications in the geometry were made. A $2 \mathrm{~m}$ level difference along the terrace was neglected, and strata thicknesses and tunnel axis level were taken as those at the intersection of the tunnel axis and the longitudinal centreline of the cottages. The top surface of the model was set at foundation level of the cottages, $600 \mathrm{~mm}$ below ground level, and $12 \mathrm{kN} / \mathrm{m}^{2}$ surcharge was applied to model self-weight of the soil above. Model boundaries were set outside the zones of influence of both the tunnel and buildings, while economising as much as possible on the size of the analysis (Figure 11), by setting vertical boundaries outside lines marking the intersections of $45^{\circ}$ planes extending outwards from the building footprint with the horizontal plane at tunnel springing level. Ground below the tunnel invert was relatively stiff and not expected to displace significantly, and therefore a shallow model depth of $20 \mathrm{~m}$ was used.

Properties for the main soil strata were obtained from the geotechnical interpretative report for the construction project. Brickearth was classified as low to intermediate plasticity silty clay, with a coefficient of consolidation of 2-6 m²/year from oedometer tests. Calculations indicated that assuming undrained behaviour during short-term tunnelling settlements was reasonable, as confirmed on site where a number of trenches for service diversions remained stable. Hand vane tests gave an average undrained strength $s_{\mathrm{u}}$ of $60 \mathrm{kPa}$, and surface wave geophysics indicated the shear modulus $G$ increasing at a

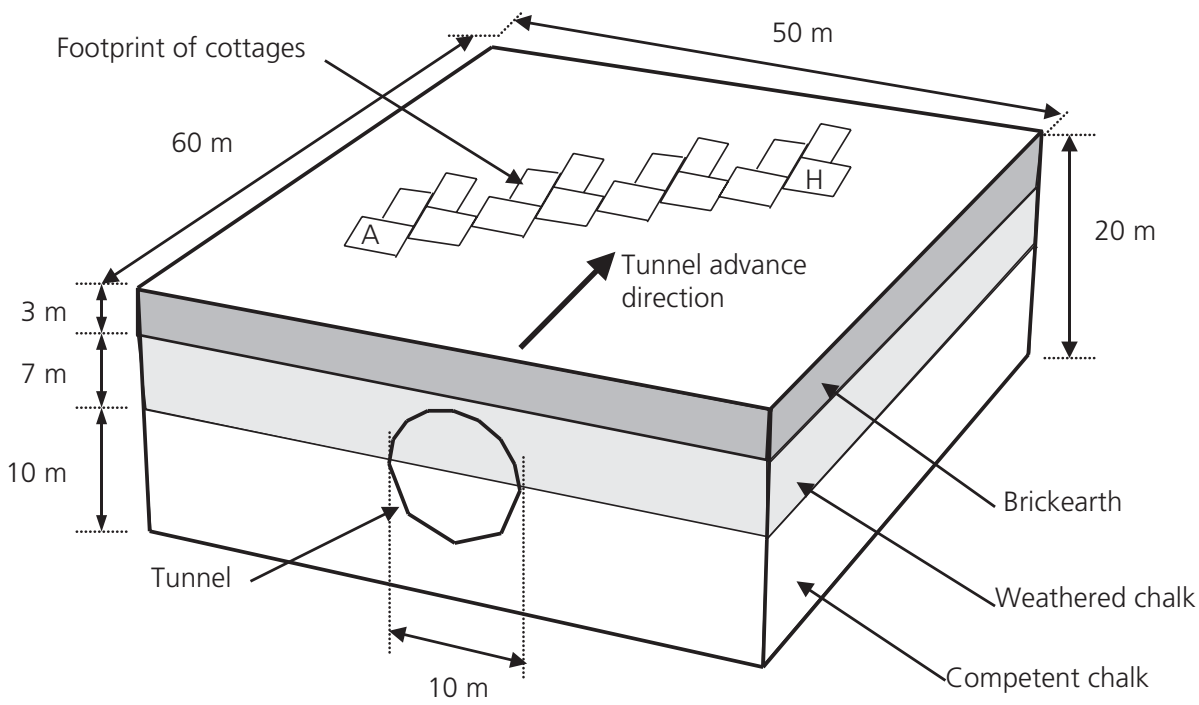

Figure 11. Geometry of model of ground and tunnel 
rate of $60 \mathrm{MPa}$ per metre depth, that is, with an average value of $90 \mathrm{MPa}$ in the $3 \mathrm{~m}$ thickness.

The weathered chalk was also classified as stiff clay, although little testing was carried out specifically on this material. As a first approximation, it was assumed to have properties intermediate between the brickearth and Upper Chalk (the latter having been extensively tested), with $G$ increasing with depth at $80 \mathrm{MPa} / \mathrm{m}$ and $s_{\mathrm{u}}$ at $40 \mathrm{kPa} / \mathrm{m}$. The multi-surface plasticity model was regarded as suitable for modelling both brickearth and weathered chalk.

The Upper Chalk was classified as a jointed rock, with $s_{\mathrm{u}}$ in the range $1000-1500 \mathrm{kPa}$. Because it lies below tunnel springing level, it was expected to have less influence on the ground movements than the other strata and so, to simplify the model, an elastic constitutive model was used. Shear modulus $G$ was taken increasing with depth at $125 \mathrm{MPa} / \mathrm{m}$ from a value of $650 \mathrm{MPa}$ at the top of the Upper Chalk, to be consistent with pressure-meter data indicating stiffness of around $1400 \mathrm{MPa}$ at $16 \mathrm{~m}$ below ground level.

Appendix 1 gives details of the parameters used in the multisurface plasticity model for the weathered clay and brickearth, and shows a simplifying assumption in which the profiles of strength and stiffness with depth for these two materials were combined.

In situ stresses were measured only in the Upper Chalk, by means of pressuremeters. Significant variability was found, with $K_{0}$ closest to the cottages ranging from 0.59 to 1.82 . Values towards the lower end of this range were expected at the cottages, owing to the depth of weathering of the chalk. In the model, the soil was allowed to settle under its own self-weight prior to tunnel excavation, causing the initial $K_{0}$ to be approximately $1 \cdot 0$.

\subsection{Tunnel}

The tunnel was modelled as straight, level and parallel to the sides of the ground block. The tunnel cross-section was approximated as a regular polygon, with eight segments above springing level and four below (Figure 11), enabling the faceted shell elements to be used for the lining. High stiffness $\left(5 \times 10^{6} \mathrm{GPa}\right)$ was used for the lining to guarantee numerical stability.

\subsection{Buildings}

The cottages were initially modelled as a staggered terrace in plan. It was decided at an early stage to neglect the rear extensions, because their effect on the transverse settlement behaviour of the terrace as a whole was thought to be small. This reduced the number of degrees-of-freedom in the model significantly. The plan layout of the main load-bearing walls of the cottages was further simplified to that shown in Figure 12. Walls were modelled using the elastic, no-tension constitutive model, with a self-weight of $20 \mathrm{kN} / \mathrm{m}^{3}$ and a Young's modulus

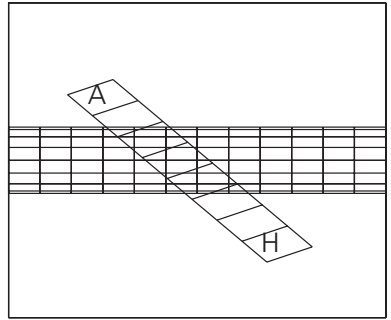

(a)

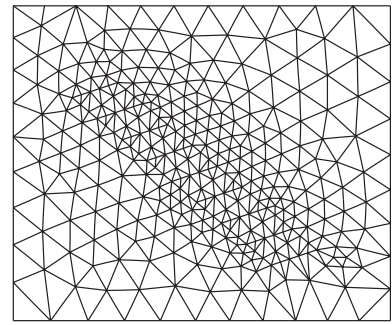

(b)
Figure 12. Final model arrangement: (a) plan of building and tunnel; (b) mesh on ground surface

of $2 \mathrm{GPa}$. More details on the stress-strain relationship and parameters for the masonry model are given in Appendix 2.

Previous research had shown the significance of openings, such as doors and windows. In the Maddox Street analyses (Bloodworth and Houlsby, 2000), openings were large and played an important role in initiating damage in a building that did not span across the whole settlement trough but was positioned in the hogging region. However, at Ramsgate the buildings spanned the entire trough and openings were more uniformly distributed. Thus, individual openings were expected to have less impact on global building behaviour than at Maddox Street. The main openings in the front and rear facades were represented as vertical regions or 'columns' of reduced stiffness, following the approach taken in Bloodworth and Houlsby (2000), as shown in Figure 13 (where $40 \%$ is chosen as the approximate percentage of solid facade remaining above and below the openings). This is similar to the concept used by Simpson (1994), although in his case rows of openings were modelled as horizontal 'strata' of reduced stiffness. Vertical 'columns' were regarded as more appropriate in this case because of the aspect ratio of the main window openings being deeper than their width and with very little masonry present across the top (Figure 3(a)).

\subsection{Overview of analyses}

The strategy was to analyse a 'greenfield' model (i.e. without the building) first and verify this against the 'greenfield' settlement trough recorded on site. The building was then introduced and a series of coupled analyses carried out. The ability of the models to reproduce the global behaviour and the amount and distribution of damage to the facades was examined.

In the analysis the tunnel was excavated in a single stage. Provision was made for the tunnel to be excavated incrementally, although this was not exploited at the time of the study due to significantly longer run times. The study focused therefore on modelling the final condition of the ground and buildings after all tunnelling was complete. 




Figure 13. Modelling of building facades

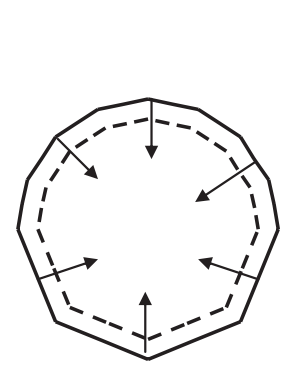

(a)

\section{Horizontal fixity to springing}

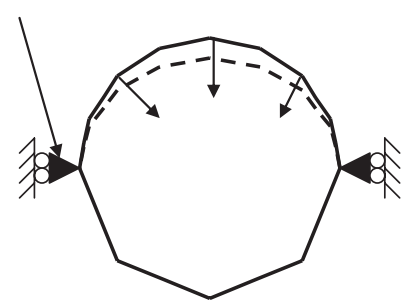

(b)
Figure 14. Options for shrinking of tunnel lining to model ground loss: (a) shrinking entire tunnel; (b) shrinking top half only

\section{6 'Greenfield' analyses}

When a trial 'greenfield' analysis was carried out with the entire lining shrunk to model $1 \%$ radial volume loss as shown in Figure 14(a), trough width parameter $i$ was $11 \mathrm{~m}$, much wider than observed on site. Because volume loss was believed to originate in the crown region, an analysis was carried out shrinking the top half of the lining only (Figure 14(b)). The resulting trough shape, with the shrinkage strain adjusted to $1 \%$ to give maximum settlement of $20 \mathrm{~mm}$, has a reduced value of $i$ of $5 \mathrm{~m}$, similar to that observed in the field (Figure 7). Troughs from the model at the front and rear of the cottages are compared with those observed in Figure 6, and contours of the surface settlements from the model are shown in Figure 15(a), indicating that the trough is reasonably uniform across the model, particularly in the central region under the building footprint where mesh discretisation is greatest. Volume loss in the 'greenfield' analysis calculated from the integral of the settlement troughs shown in Figure 6 is $0 \cdot 21 \%$ at the front of the cottages and $0 \cdot 20 \%$ at the rear, which is similar to the site observations.
When the top half only of the lining was shrunk, horizontal fixity was introduced at springing level, as shown in Figure 14(b), to ensure the desired distorted shape with top half lining shrinkage was indeed achieved. The presence of this fixity virtually eliminated any lining movement below springing level. This was felt to be an acceptable approximation, given the presence of competent chalk in the lower half of the heading and rock bolting in the haunch areas.

\subsection{Coupled analyses including building}

Analyses were carried out to examine the influence of internal party walls and openings and compare masonry and elastic material models for the building, as summarised in Table 2.

The elastic analysis with the party walls, C4, would be expected to exhibit the stiffest building response. Even in this model, however, ground settlements were not modified significantly compared to the 'greenfield' case (Figure 15(b)), indicating that the long and not very tall terrace is relatively flexible in longitudinal bending.

Comparison of analyses $\mathrm{C} 1$ and $\mathrm{C} 2$ shows that modelling openings by vertical regions of reduced stiffness significantly reduces the damage (Figure 16). In the sagging region, damage is concentrated along the bottom edge of the facade. In the hogging region, some damage is initiated from the top on one side of the trough.

The effect of adding the party walls (analysis C3) is significantly to reduce damage severity, to levels more similar to what was observed on site (Figure 17). The figure shows an alternative method of visualising the damage by crack patterns, in which a single line is drawn (in the direction of the crack) at each integration point for which cracking strain exceeds 


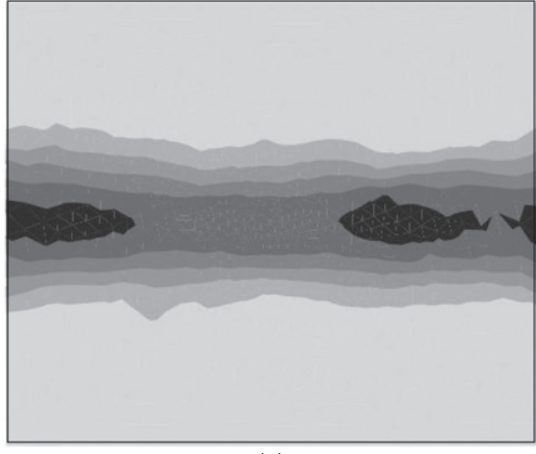

(a)

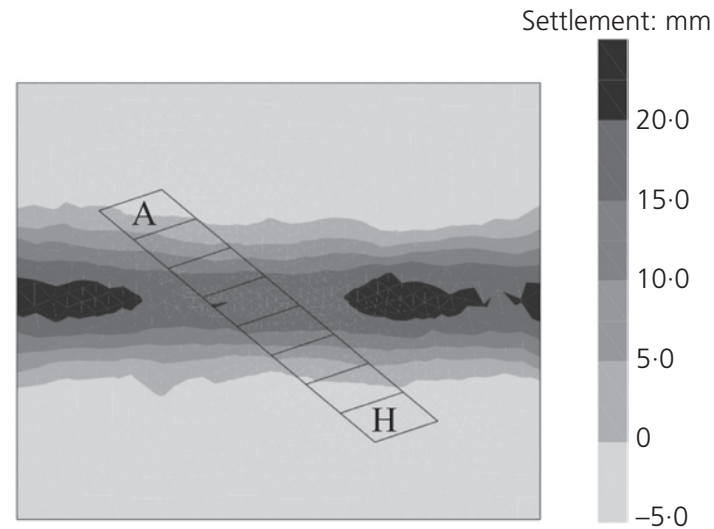

(b)

Figure 15. Contours of ground settlements from (a) 'greenfield' model and (b) coupled finite-element model with elastic building

\begin{tabular}{|c|c|c|c|}
\hline Analysis & Facade layout & Regions of reduced stiffness for openings & Material model \\
\hline $\mathrm{C} 1$ & No party walls & No & Masonry \\
\hline $\mathrm{C} 2$ & No party walls & Yes, $40 \%$ stiffness & Masonry \\
\hline $\mathrm{C} 3$ & arty walls & Yes, 40\% stiffness & Masonry \\
\hline $\mathrm{C} 4$ & arty walls & Yes, 40\% stiffness & Elastic \\
\hline
\end{tabular}

$500 \mu \varepsilon$. A second parallel line is drawn when the cracking strain exceeds $1000 \mu \varepsilon$, a third at $1500 \mu \varepsilon$ and so on, and thus these plots show both magnitude and direction of cracking (in this particular figure, the vast majority of cracks indicated are by single lines, that is, $500-1000 \mu \varepsilon$ ). In the hogging region, cracking is generally vertical, consistent with a bending analogy. However, in the sagging region, cracking suggests arching occurring low down in the facades, protecting the upper part of the facade from damage. Arching, a function of axial stiffness of the facade and horizontal restraint to its base, is not taken into account in deep beam theory, and there is some evidence for it in the two low-level cracks D7 and D21 above the tunnel that showed closing, where tension would be expected in a deep beam model.
Because of the smeared cracking model, crack patterns obtained from the model should not be interpreted as indicating specific crack locations. Smoothing may therefore be applied to the finite-element analysis results to indicate broad regions in which cracking damage is likely. Figure 18 shows the result of this if the strains in Figure 17 are averaged over regions half the height of the facades. Maximum cracking strains averaged in this way are in the range $0 \cdot 1-0 \cdot 15 \%$.

Figure 19 shows the facade results for the elastic model, analysis C4. In this case, damage category is correlated with maximum tensile strain in accordance with Burland et al. (1977). Damage is less severe than with the masonry material, and is concentrated in shear deformation in the regions of reduced 


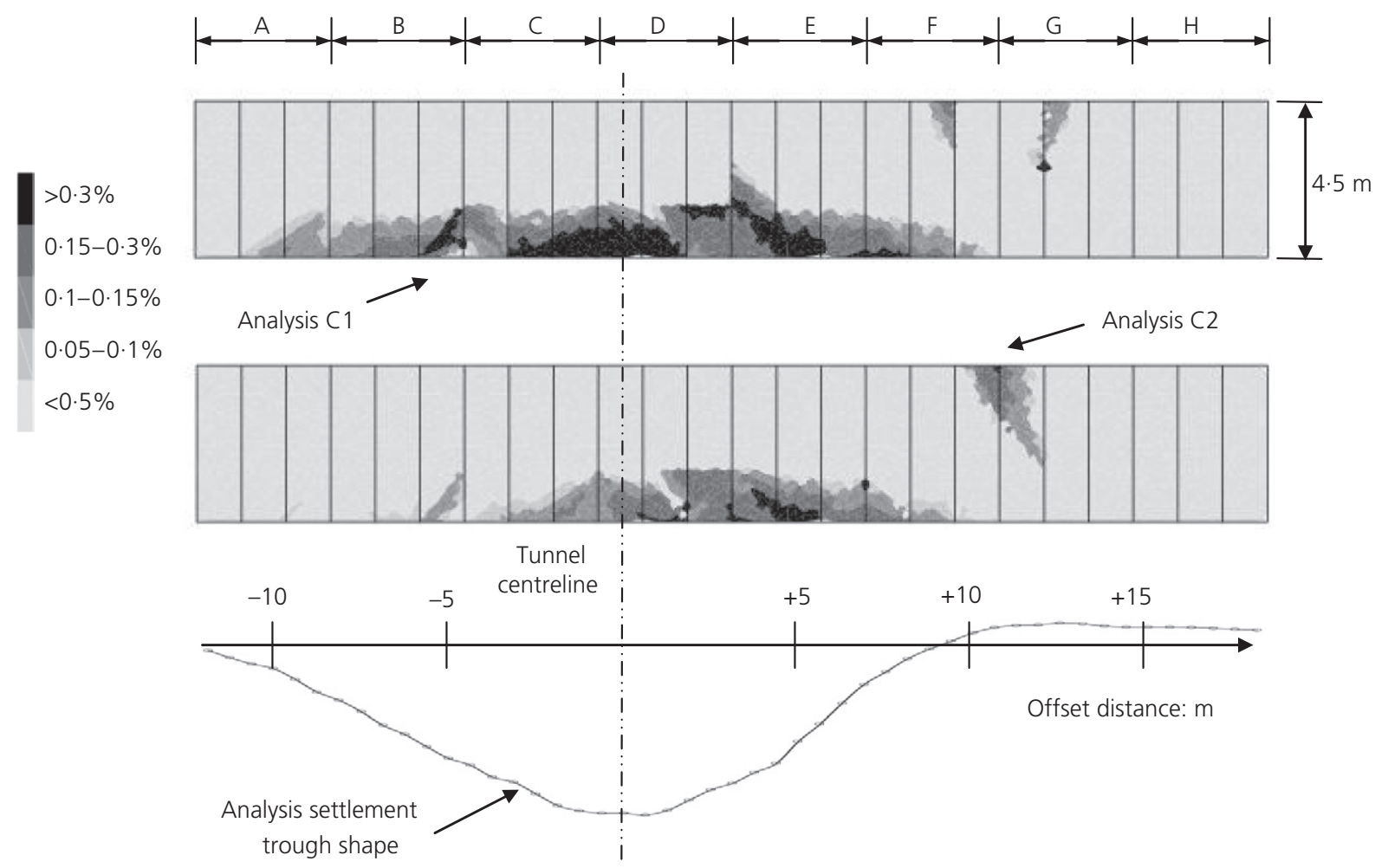

Figure 16. Contours of cracking strain for front facades (analyses without party walls)

stiffness. Because no cracking and loss of stiffness take place, there is no redistribution of damage along the facades and so it remains concentrated close to the tunnel axis. This agrees less well than the masonry model results with the distribution of movements observed on existing cracks on site.

Analysis C3 predicted very light damage for the party walls $(<0.05 \%$ cracking strain), except for the two between cottages $\mathrm{C} / \mathrm{D}$ and $\mathrm{D} / \mathrm{E}$ that are positioned close to the tunnel axis and entirely within the sagging region of the settlement trough. In the model, damage is concentrated at the ends of the party walls (Figure 20), initiated by the vertical restraint from the adjoining facades.

New cracking observed on site in the party wall between cottages C and D is also indicated in Figure 20. Both of these cracks appeared to propagate down from the top, consistent with hogging deformation of the party wall. Final measured differential settlement between front and rear was about $3 \mathrm{~mm}$, approximately $1 / 2000$ of the wall length and not enough to cause the observed damage. However, during the approach of the tunnel on 5 February, the front end of the party wall had settled by $11 \mathrm{~mm}$, whereas the rear had not moved significantly, causing differential settlement about $1 / 850$ of the wall length - more consistent with the observed damage. It is likely that better agreement between model and field would have been obtained for the party walls if incremental tunnel advance had been modelled.

\section{Conclusions}

The Ramsgate tunnel provides an unusual opportunity to study the behaviour of a row of typical houses subjected to tunnelling at very low cover beneath but without intervention measures such as compensation grouting. It was found that the terrace responded flexibly to the tunnel-induced settlements, with movements recorded at existing cracks strongly correlated with the passage of the tunnel, together with a small number of new cracks. Only some of the individual crack movements can be explained in terms of the current theory of building facades acting as deep beams. Overall, damage was less severe than predicted by current analyses, and in particular, significant opening of cracks at the top of the facades in the key hogging region was not observed.

A three-dimensional model of the site was analysed. It was possible to reproduce the observed 'greenfield' settlement trough for the particular tunnelling method being employed. The model confirmed the flexible transverse behaviour of the terrace. The best structural model for the buildings proved to be one using a no-tension material model for masonry, which included internal structural walls and the effects of openings in reducing structural stiffness. The model results showed arching 


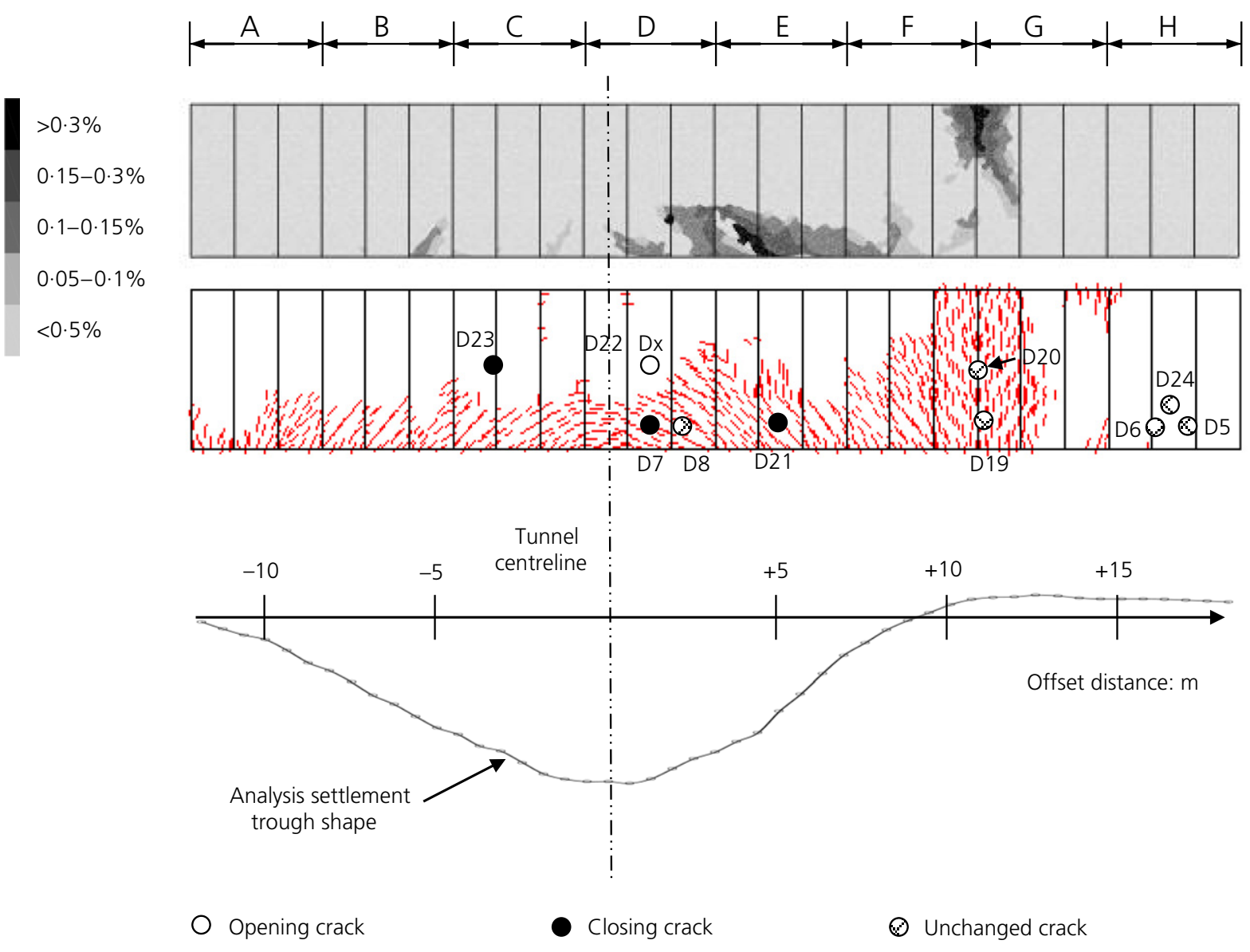

Figure 17. Cracking strain and crack patterns for front facades, for analysis C3 with party walls, including locations of opening and closing pre-existing cracks

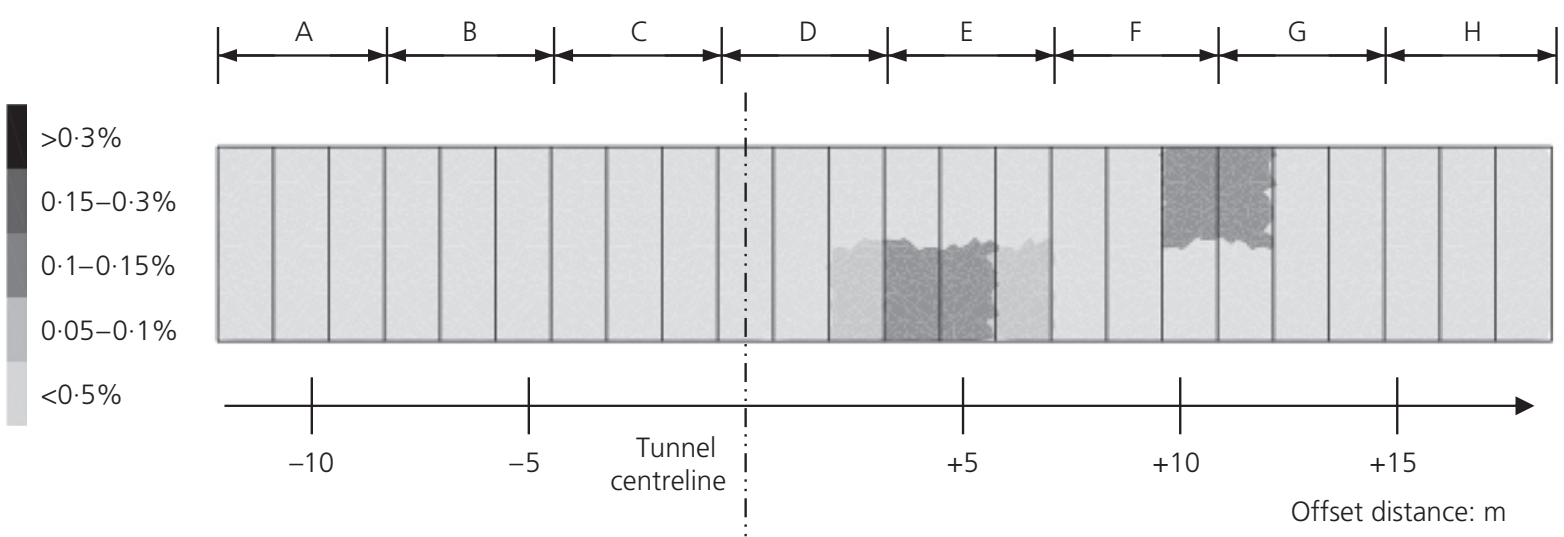

Figure 18. Averaged cracking strains for analysis with party walls, analysis C3

occurring in the building facades over the tunnel, not taken into account in deep beam theories, but for which there was some evidence in the field data.
The model allowed for interactions between the buildings and the ground. Although in this instance the buildings were sufficiently flexible that they had little influence on the settlement 


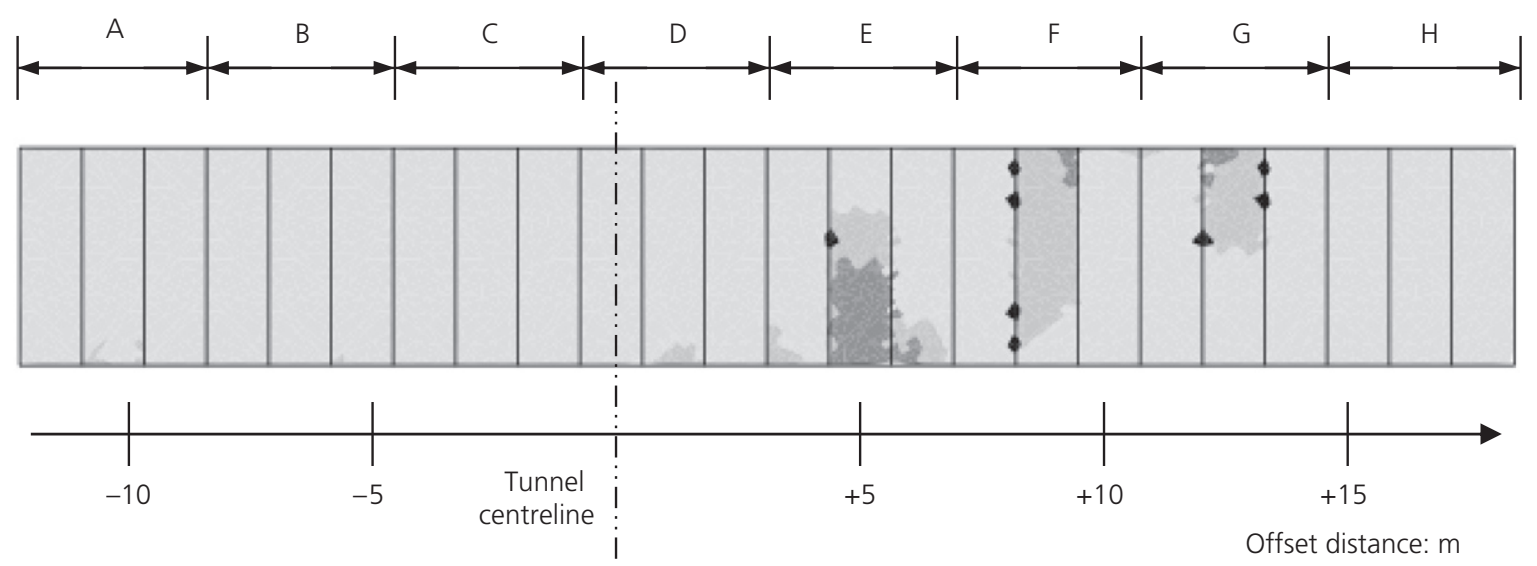

Severe $(>0 \cdot 3 \%)$

Moderate $(0 \cdot 15-0 \cdot 3 \%)$

Slight $(0 \cdot 1-0 \cdot 15 \%)$

Very slight $(0 \cdot 05-0 \cdot 1 \%)$

Negligible $(<0 \cdot 5 \%)$

Figure 19. Damage categories derived from maximum tensile strain for elastic model C4
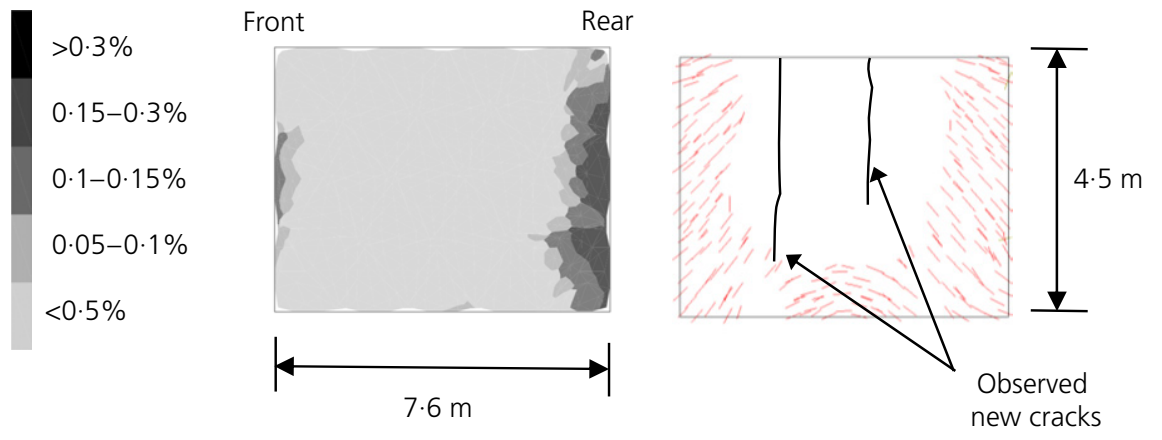

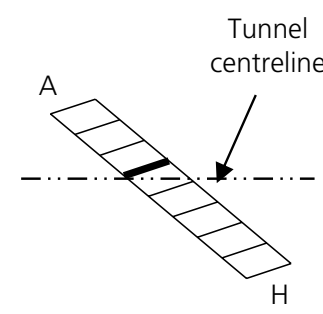

Plan showing wall location

Figure 20. Predicted (analysis C3) and observed damage to party wall between cottages $C$ and $D$

pattern, this would not always be the case. To predict correctly damage to walls aligned with the direction of tunnelling, it would be necessary to model the three-dimensional incremental advance of the tunnel heading, which should be possible with increased computing power. Thus the comparison between the field data of this case history and the numerical model exposes some of the limitations of numerical techniques to modelling the full complexity of real structural behaviour, while capturing some of the essential features of the observations.

\section{Acknowledgements}

The first author is grateful for the support of Kellogg Brown \& Root and the Royal Commission for the Exhibition of 1851, from whom he was in receipt of an Industrial Fellowship. The authors acknowledge the support and assistance of the site supervision team at the Ramsgate Harbour Approach Road tunnel site, including staff from Babtie, Taylor Woodrow Construction and Perforex S.A. Calculations were carried out at the Oxford Supercomputing Centre, using code substantially written by Harvey Burd, Charles Augarde and Liu Gang. 


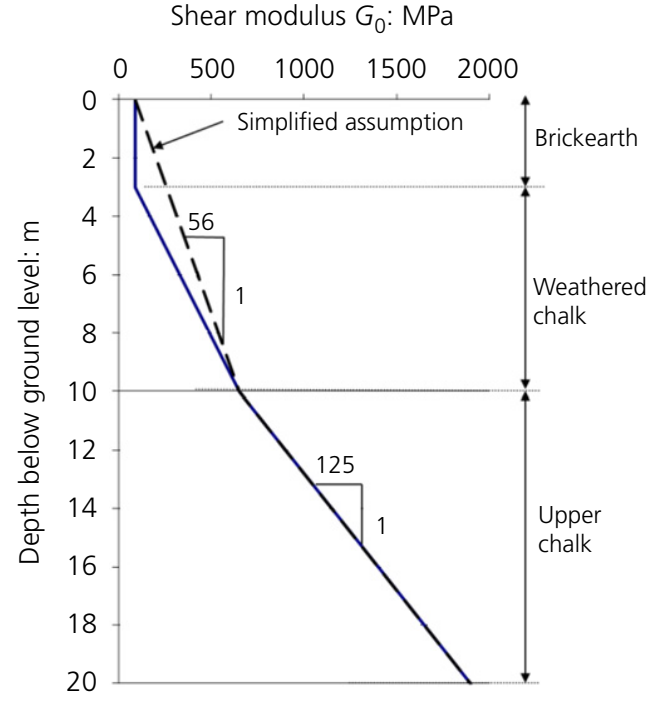

(a)

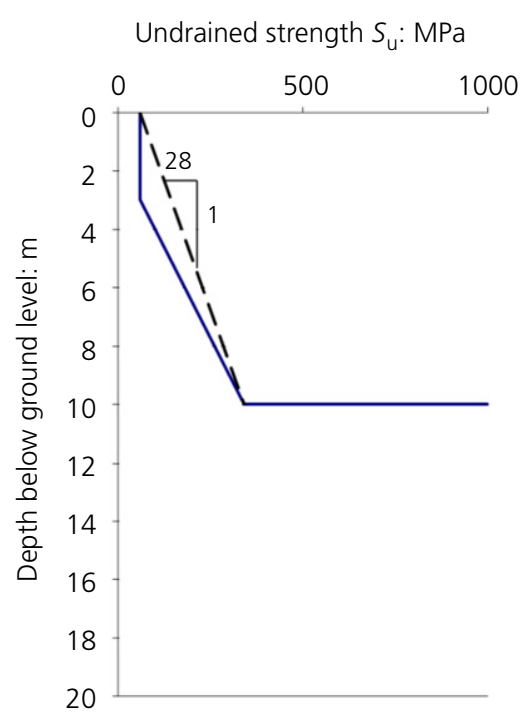

(b)

Figure 21. Modelling assumptions for geotechnical parameters:

(a) variation of shear modulus with depth; (b) variation of undrained strength with depth

\begin{tabular}{llllllllll}
\hline Surface & 1 & 2 & 3 & 4 & 5 & 6 & 7 & 8 & 9 \\
\hline$c_{\alpha}$ & 0.02 & 0.04 & 0.06 & 0.1 & 0.15 & 0.2 & 0.3 & 0.5 & 0.7 \\
$g_{\alpha}$ & 0.9 & 0.75 & 0.5 & 0.3 & 0.2 & 0.15 & 0.1 & 0.05 & 0.025
\end{tabular}

Table 3. Values of non-dimensional parameters defining yield surfaces

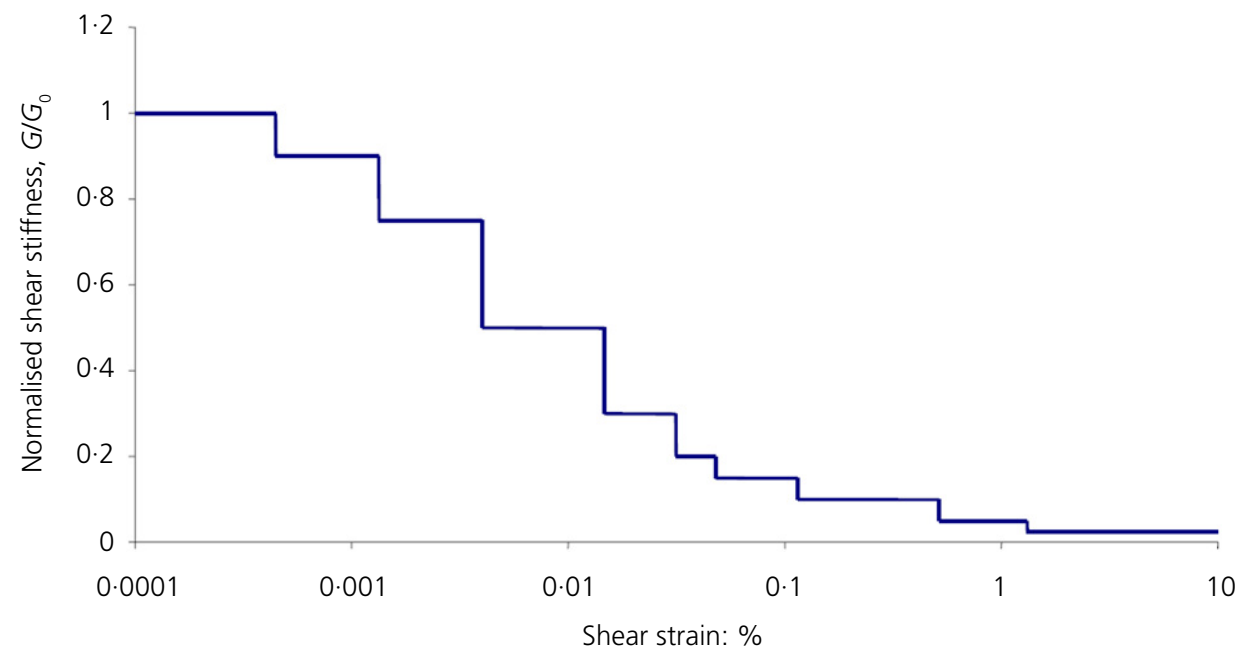

Figure 22. Reduction of shear stiffness with shear strain for nine-surface kinematic hardening soil model 


\section{Appendix 1. Multi-surface plasticity soil model} The soil model used to model the brickearth and weathered clay at Ramsgate is one designed for the modelling of the undrained behaviour of clays (Houlsby, 1999). It takes into account the non-linear behaviour of the soil at small strains, and also includes effects such as hysteresis and stiffness dependence on recent stress history, by means of multiple kinematic hardening yield surfaces (in this case nine, plus a bounding von Mises perfectly plastic failure surface).

The parameters required to define the model are the initial shear modulus at very small strain $G_{0}$, the bulk modulus $K$ (chosen to be a large factor of approximately 50 times $G_{0}$ by taking Poisson ratio equal to 0.49 for undrained analysis) and the undrained shear strength $s_{\mathrm{u}}$, together with non-dimensional pairs of numbers $c_{\alpha}$ and $g_{\alpha}$ that define the shear strength and tangent shear stiffness for each yield surface as a proportion of $s_{\mathrm{u}}$ and $G_{0}$ respectively. The parameter pairs $\left(c_{\alpha}, g_{\alpha}\right)$ model the degradation of shear stiffness with shear stress (or shear strain) with a relationship typical of most soils (Houlsby, 1999).

Figure 21 shows the simplifying assumption made for the profiles of initial shear modulus $G_{0}$ and undrained shear strength $s_{\mathrm{u}}$ with depth in the brickearth and the weathered clay, based on the site data. The $\left(c_{\alpha}, g_{\alpha}\right)$ pairs for the nine nested yield surfaces are given in Table 3, and Figure 22 shows their implication in terms of reduction of shear stiffness with shear strain.

\section{Appendix 2. Masonry elastic no-tension material model}

Figure 23 shows the stress-strain relationship for the masonry material model. The values of the parameters used in the model of the Ramsgate buildings are given in Table 4. Values of the parameters $c$ and $f_{1}$ are chosen merely to ensure

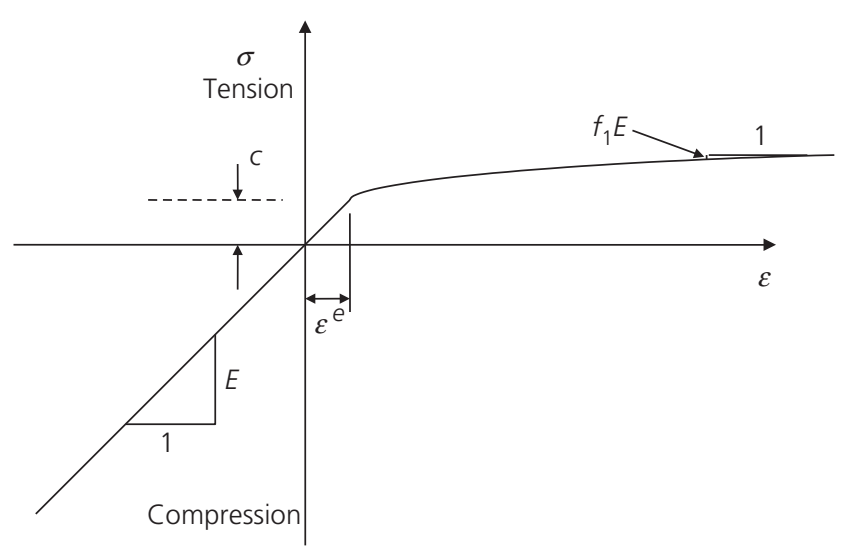

Figure 23. Stress-strain $(\sigma-\varepsilon)$ relationship for elastic no-tension masonry constitutive model

\begin{tabular}{lcccc}
\hline $\begin{array}{l}\text { Young's } \\
\text { modulus, } \\
\text { E: GPa }\end{array}$ & $\begin{array}{c}\text { Poisson's } \\
\text { ratio, } v\end{array}$ & $\begin{array}{c}\text { Notional } \\
\text { tensile } \\
\text { strength, } \\
\text { c: kPa }\end{array}$ & $\begin{array}{c}\text { Tensile } \\
\text { cracking } \\
\text { strain, } \varepsilon^{e}\end{array}$ & $\begin{array}{c}\text { Young's } \\
\text { modulus } \\
\text { reduction } \\
\text { factor, } f_{1}\end{array}$ \\
\hline 2.0 & 0.2 & 10.0 & $5.0 \times 10^{-6}$ & 0.01
\end{tabular}

Table 4. Masonry no-tension material model parameters

numerical stability as the crack is formed, and are not intended to model the real tensile behaviour of masonry.

\section{REFERENCES}

Augarde CE and Burd HJ (2001) Three-dimensional finite element analysis of lined tunnels. International Journal for Numerical and Analytical Methods in Geomechanics 25(3): 243-262.

Bloodworth AG (2002) Three-Dimensional Analysis of Tunnelling Effects on Structures to Develop Design Methods. DPhil thesis, University of Oxford, Oxford, UK.

Bloodworth AG and Houlsby GT (2000) Three-dimensional analysis of building settlement caused by shaft construction. In Proceedings of International Symposium on Geotechnical Aspects of Underground Construction in Soft Ground (Kusakabe O, Fujita K and Miyazaki Y (eds)). Balkema, Rotterdam, The Netherlands, pp. 607-612.

Boscardin MD and Cording EJ (1989) Building response to excavation-induced settlement. Journal of Geotechnical Engineering, ASCE 115(1): 1-21.

Bougard JF (1988) Mechanical pre-cutting method. Tunnelling and Underground Space Technology 3(2): 163-167.

Burd HJ, Houlsby GT, Augarde CE and Liu G (2000) Modelling the effects on masonry buildings of tunnelling-induced settlement. Proceedings of the Institution of Civil Engineers - Geotechnical Engineering 143(1): 17-29, http://dx.doi.org/10.1680/geng.2000.143.1.17.

Burland JB and Wroth CP (1975) Settlement of buildings and associated damage. In Proceedings of Conference on Settlement of Structures. Pentech Press, London, UK, pp. 611-654.

Burland JB, Broms BB and de Mello VFB (1977) Behaviour of foundations and structures. In Proceedings of the 9th ICSMFE (Kogakkai D (ed.)). Japanese Society of Soil Mechanics and Foundation Engineering, Tokyo, Japan, vol. 3, pp. 495-546.

Burland JB, Standing JR and Jardine FM (eds) (2001) Building Response to Tunnelling. Case Studies from the Jubilee Line Extension, London. Volumes 1 and 2. Thomas Telford, London, UK.

CIRIA (Construction Industry Research and Information Association) (1994) Foundations in Chalk. Ciria, London, UK, Project Report No. 11. 
Crow MR and Newman TG (1999) Tunnelling using the pre-vaulting system in chalk for the Ramsgate Harbour Approach Tunnel, United Kingdom. In Proceedings of International Symposium on Tunnel Construction and Piling '99. Brintex Ltd, London, UK, pp. 324-328.

Farrell R, Mair R, Sciottic A and Pigorini A (2014) Building response to tunnelling. Soils and Foundations 54(3): 269-279.

Franzius JN, Potts DM, Addenbrooke TI and Burland JB (2004) The influence of building weight on tunnelling induced ground and building deformation. Soils and Foundations 44(1): 25-38.

Frischmann WW, Hellings JE and Snowden C (1994) Protection of the Mansion House against damage caused by ground movements due to the Docklands Light Railway Extension. Proceedings of the Institution of Civil Engineers - Geotechnical Engineering 107(2): 65-76, http://dx.doi.org/10.1680/igeng.1994.26374.

Houlsby GT (1999) A model for the variable stiffness of undrained clay. In Proceedings of International Symposium on Pre-Failure Deformation of Soils (Jamiolkowski M, Lancellotta R and Lo Presti D (eds)). Balkema, Rotterdam, The Netherlands, vol. 1, pp. 443-450.

Houlsby GT, Liu G and Augarde CE (2000) A tying scheme for imposing displacement constraints in finite element analysis. Communications in Numerical Methods in Engineering 16(10): 721-732.

Huntley SL, Holtrieger PJ, Jewell PJ and Macklin SR (1997) Ground investigations for the Ramsgate Harbour Approach Road Tunnel - planning, procurement, evaluation and interpretation. In Proceedings of International Symposium on Tunnelling '97. Institution of Mining and Metallurgy, London, UK, pp. 185-210.

Mair RJ (1993) Developments in geotechnical engineering research: application to tunnels and deep excavations. Proceedings of the Institution of Civil Engineers - Civil Engineering 93(1): 27-41.

Mair RJ, Taylor RN and Burland JB (1996) Prediction of ground movements and assessment of risk of building damage due to bored tunnelling. In Proceedings of International Symposium on Geotechnical Aspects of Underground Construction in Soft Ground (Mair RJ and Taylor RN (eds)). Balkema, Rotterdam, The Netherlands, pp. 713-718.

Martareche F (2013) The perforex pre-cutting method: an inventive tunnel construction technique maximizing safety for the workers and surroundings. In Proceedings of 13th World Conference on ACUUS: Advances in Underground Space Development, ACUUS 2012 (Zhou Y, Cai J and Sterling R (eds)). Research Publishing, Singapore, Singapore, pp. 1141-1148.

Morgan SR (1999) Prevaulting success at Ramsgate Harbour. Tunnels and Tunnelling International 31(7): 31-34.
Mroueh H and Shahrour I (2002) Three-dimensional finite element analysis of the interaction between tunnelling and adjacent structures. In Proceedings of International Symposium on Geotechnical Aspects of Underground Construction in Soft Ground, Toulouse, France (Kastner R, Dias D, Emeriaut F and Guilloux A (eds)). Specifique, Lyon, France, pp. 729-734.

Newman TG and Ingle JL (2002) A comparison between tube-à-manchette and lance grouting to assist tunnel excavation in chalk. Proceedings of the Institution of Civil Engineers - Geotechnical Engineering 155(3): 175-186, http://dx.doi.org/10.1680/geng.2002.155.3.175.

Newman TG, Allen RG and Mortimore RN (2003) Geological modelling, the observational method and management of ground hazards: Ramsgate Harbour Approach Road Tunnel. Quarterly Journal of Engineering Geology and Hydrogeology 36(1): 35-50.

Peck RB (1969) Deep excavations and tunnelling in soft ground. In Proceedings of the 7th ICSMFE, State-of-the-Art Volume. Sociedad Mexicana de Mecánica de Suelos, Mexico City, Mexico, pp. 225-290.

Phaal R and Calladine CR (1992) A simple class of finite elements for plate and shell problems II: an element for thin shells, with only translational degrees of freedom. International Journal of Numerical Methods in Engineering 35(5): 979-996.

Pickhaver JA, Burd HJ and Houlsby GT (2010) An equivalent beam method to model masonry buildings in $3 \mathrm{D}$ finite element analysis. Computers and Structures 88(19-20): 1049-1063.

Simpson B (1994) A model of interaction between tunnelling and a masonry structure. In Proceedings of the 3rd European Conference on Numerical Methods in Geotechnical Engineering, ECONMIG '94 (Smith IM (ed.)). Balkema, Rotterdam, The Netherlands, pp. 221-228.

Wisser C, Augarde CE and Burd HJ (2001) Three-dimensional finite element analysis of compensation grouting. In Computer Methods and Advances in Geomechanics, Proceedings of IACMAG 10, Tucson, AZ, USA (Desai CS, Contractor D, Harpalani S, Kundu T and Kemeny J (eds)). Balkema, Rotterdam, The Netherlands, pp. 1731-1736.

\section{HOW CAN YOU CONTRIBUTE?}

To discuss this paper, please email up to 500 words to the editor at journals@ice.org.uk. Your contribution will be forwarded to the author(s) for a reply and, if considered appropriate by the editorial board, it will be published as discussion in a future issue of the journal.

Proceedings journals rely entirely on contributions from the civil engineering profession (and allied disciplines). Information about how to submit your paper online is available at www.icevirtuallibrary.com/page/authors, where you will also find detailed author guidelines. 